\title{
Fixed Point Theorems in Symmetric Spaces and Invariant Approximations
}

\author{
Rajeshri Rana \\ Asst. Prof. \\ Applied Science and \\ Humanities Department \\ G.B.Pant Engineering College, \\ Pauri 246001, India
}

\author{
R. C. Dimri \\ Professor \\ Department of Mathematics \\ Birla Campus, \\ H. N. B. Garhwal Central \\ Univ., Srinagar -Garhwal, \\ India.
}

\author{
Anita Tomar \\ Asst. Prof. \\ Department of Mathematics \\ Govt. Degree College \\ Dakpathar, Vikasnagar, \\ Dehradun, India.
}

\begin{abstract}
We present common fixed point theory for generalized weak contractive condition in symmetric spaces under strict contractions and obtain some results on Invariant Approximations.
\end{abstract}

\section{Keywords}

Symmetric spaces, (E.A.) property, Compatible mappings, Weak Compatible mappings, Weak contractive condition, Occasionally weakly compatible maps.

\section{INTRODUCTION}

With the advent of notion of compatible maps introduced by Jungck[8], the study of common fixed point theorems for contractive maps has centered around the study of compatible maps and its weaker forms. On the other hand, the study of noncompatible maps is also equally interesting. Pant[13], Aamri and Moutawkil[1] and others have initiated wonderful works in this field.

It has been observed [6] that some of defining properties of metric are not needed in proofs of certain metric theorems. Motivated by this fact, Hicks [6] established fixed point theorems in symmetric spaces. Recall that a symmetric on a set $\mathrm{X}$ is a non negative real valued function $\mathrm{d}$ on $\mathrm{X} \times \mathrm{X}$. such that

(i) $d(x, y)=0$ if and only if $x=y$

(ii) $d(x, y)=d(y, x)$.

Let $\mathrm{d}$ be a symmetric on set $\mathrm{X}$ and for $r>0$, let $B(x, r)=\{y \in X: d(x, y)<r\}$. A topology $t(d)$ on $\mathrm{X}$ is given by $U \in t(d)$, if and only if for each $x \in U, B(x, r) \subset U$, for some $r>0$. A symmetric $\mathrm{d}$ is a semimetric if for each $x \in X$ and each $r>0, B(x, r)$ is a neighbourhood of $\mathrm{x}$ in topologyt $(d)$. We have $\operatorname{Lim}_{n \rightarrow \infty} d\left(x_{n}, x\right)=0$ if and only if $x_{n} \rightarrow x$ in topology $t(d)$.

The following two axioms given by Wilson [18]. Let $(X, d)$ be a symmetric space:
(W.3): Given $\left\{x_{n}\right\}, x$ and $y$ in $\mathrm{X}$, then $\operatorname{Lim}_{n \rightarrow \infty} d\left(x_{n}, x\right)=0$ and $\operatorname{Lim}_{n \rightarrow \infty} d\left(x_{n}, y\right)=0$ implies that $x=y$.

(W.4): Given $\left\{x_{n}\right\}, x$ and $y$ in $\mathrm{X}$, then $\operatorname{Lim}_{n \rightarrow \infty} d\left(x_{n}, x\right)=0 \&$ $\operatorname{Lim}_{n \rightarrow \infty} d\left(x_{n}, y_{n}\right)=0$ implies that, $\operatorname{Lim}_{n \rightarrow \infty} d\left(y_{n}, x\right)=0$.

\section{PRELIMINARIES}

Sessa[16] introduced the concept of weak commuting maps in metric spaces. Jungck[8] extended his concept in the following way:

Definition 1.1: Let $\mathrm{f}$ and $\mathrm{T}$ be the two self mappings of symmetric space $(X, d)$, then $\mathrm{f}$ and $\mathrm{T}$ are said to be compatible if $\operatorname{Lim}_{n \rightarrow \infty} d\left(f T x_{n}, T f x_{n}\right)=0$ whenever $\left\{x_{n}\right\}$ is a sequence in $\mathrm{X}$, such that $\operatorname{Lim}_{n \rightarrow \infty} f x_{n}=\operatorname{Lim}_{n \rightarrow \infty} T x_{n}=t$, for each $t \in X$.

Obviously two weak commuting mappings are compatible but converse is not true[8]. Recently, Jungck[7] introduced the concept of weak compatible maps as follows:

Definition 1.2: Let $\mathrm{f}$ and $\mathrm{T}$ be the two self mappings of symmetric space $(X, d)$, then $\mathrm{f}$ and $\mathrm{T}$ are said to be weakly compatible if they commute at their coincidence points i.e. if $f u=T u$ for some $u \in X$ then $f T u=T f u$. Also, we have that two compatible maps are weakly compatible but converse is not true.

In 2006, Jungck and Rhoades [9] gave some theorems on Occasionally weakly compatible maps. Recently in 2008, M. A. Al-Thagafi and N. Shahzad [19] defined the concept of Occasionally weakly compatible maps and applied it for invariant approximations

Definition 1.3: Two self maps $f: X \rightarrow X$ and $T: X \rightarrow X$ are said to be occasionally weakly compatible if and only if there exists some point $x$ in $\mathrm{X}$, such that $f x=T x$ 
at which $f$ and $\mathrm{T}$ commute. In other words, for $T x \in f X$, we have $T f x \subseteq f T x$

Example: Let $X=[0, \infty)$ with usual metric. Define $f: X \rightarrow X$ and $T: X \rightarrow X$ by

$f x=\left\{\begin{array}{ll}0 & ; 0 \leq x<1 \\ 2 x & ; 1 \leq x<\infty\end{array} \quad, T x= \begin{cases}x & ; 0 \leq x<1 \\ (1,1+4 x) & ; 1 \leq x<\infty\end{cases}\right.$

It can be verified that $x=1$ is the coincidence point of $\mathrm{f}$ and $\mathrm{T}$, but $f$ and $T$ are not weakly compatible, however $\{f, T\}$ is occasionally weakly compatible.

Aamri and Moutawkil [1] proved some common fixed point theorems under strict contractions on metric space, satisfying (E.A.) property.

Definition 1.4: Two self maps $\mathrm{f}$ and $\mathrm{T}$ of a metric space $(X, d)$ is said to satisfy property (E.A.), if there exists a sequence $\left\{x_{n}\right\}$, $x$ in X, such that $\operatorname{Lim}_{n \rightarrow \infty} f x_{n}=\operatorname{Lim}_{n \rightarrow \infty} T x_{n}=t$, for some $t \in X$.

Clearly, a pair of compatible as well as noncompatible self mappings of a metric space $(X, d)$ satisfies property (E.A.). In general, a pair enjoying (E.A.) property need not follow pattern of containment of range of one map into range of other map but relaxes it such requirements.

Meinardus[12] introduced the notion of Invariant approximation. Brosowski[5] initiated the study of invariant approximation, using fixed point theory and thereafter subsequent valuable results have now appeared in literature of approximation theory $[4,16]$.

Definition 1.5: Let $S$ be a subset of metric $X$. The set $P_{S}(x)=\{x \in S: d(x, y)=\operatorname{dist}(y, S)\}$ is called the set of best approximations to $\mathrm{y}$ in $\mathrm{X}$, out of $\mathrm{S}$, where $\operatorname{dist}(y, S)=\inf \{d(z, y): z \in S\}$.

The main aim of this paper is to get coincidence point for two self maps, satisfying generalized weak contractive condition, under strict contractions in symmetric spaces. Besides this, we will satisfy the convergence for modified Mann Iteration and Ishikawa Iteration. As an application we will also obtain some results on existence of common fixed points from the set of best approximations.

Alber and Guerre Delabriere[3] coined the term weakly contractive maps and obtained fixed points in Hilbert spaces. Rhoades[14] extended his result to Banach spaces. So, we have few more definitions:

Definition 1.6: Let $X$ be a metric space. A mapping $T: X \rightarrow X$ is said to be weakly contractive with respect to $f: X \rightarrow X \quad$ if for each $\mathrm{x}, \mathrm{y}$ in $\mathrm{X}$, there exists $d(T x, T y) \leq d(f x, f y)-\psi(d(f x, f y))$, where

$$
\psi:[0, \infty) \rightarrow[0, \infty), \psi(0)=0 \text { and } \operatorname{Lim}_{n \rightarrow \infty} \psi(t)=\infty \text {. }
$$

Definition 1.7: Let $X$ be a Banach space and let $T$ be weakly contractive mapping with respect to $f$, on $X$, under strict contractions. Let $\mathrm{f}(\mathrm{X})$ be a convex subset of $\mathrm{X}$. Define a

sequence $\left\{y_{n}\right\}$ in $\mathrm{f}(\mathrm{X})$ as

$y_{n}=f\left(x_{n+1}\right)=\left(1-\alpha_{n}\right) f\left(x_{n}\right)+\alpha_{n} g\left(x_{n}\right) ; x_{0} \in X: n \geq 0$

Definition 1.8: Let $X$ be a Banach space and let $T$ be weakly contractive mapping with respect to $f$, on $X$, under strict contractions. Assume that $\mathrm{f}(\mathrm{X})$ be a convex subset of $\mathrm{X}$. Define a sequence $\left\{y_{n}\right\}$ and $\left\{z_{n}\right\}$ in $\mathrm{f}(\mathrm{X})$ as: $z_{n}=f\left(x_{n+1}\right)=\left(1-\alpha_{n}\right) f\left(x_{n}\right)+\alpha_{n} T\left(w_{n}\right)$

$y_{n}=f\left(w_{n}\right)=\left(1-\beta_{n}\right) f\left(x_{n}\right)+\beta_{n} T\left(x_{n}\right) ; n \geq 0$ where

$0 \leq \alpha_{n}<1,0<\beta_{n} \leq 1$, for each n, $x_{0} \in X$

\section{MAIN RESULTS}

Theorem 2.1: Let $(X, d)$ be a symmetric space and let $\mathrm{T}$ be a weakly contractive mapping with respect to $f$, such that (i) $T(X) \subset f(X)$ (ii) f and $\mathrm{T}$ satisfy (E,A.) property (iii) $\mathrm{f}(\mathrm{X})$ is a complete subspace of $X$, then (a) The pair (f,T) has a point of coincidence

(b) The pair $(\mathrm{f}, \mathrm{T})$ has common fixed point provided it is occasionally weakly compatible.

Proof: Part I: Let $x_{0}$ be any arbitrary point in X. Choose a point $x_{1}$ in $\mathrm{X}$, we obtain $x_{n+1}$ in $\mathrm{X}$, such that $T\left(x_{n}\right)=f\left(x_{n+1}\right)$.

Consider $\quad d\left(f\left(x_{n+1}\right), f\left(x_{n+2}\right)\right)=d\left(T\left(x_{n}\right), T\left(x_{n+1}\right)\right)$ $\leq d\left(f\left(x_{n+1}\right), f\left(x_{n+2}\right)\right)-\psi d\left(f\left(x_{n+1}\right), f\left(x_{n+2}\right)\right)[2.1]$

Here we have $\left\{d\left(f\left(x_{n+1}\right), f\left(x_{n+2}\right)\right)\right\}$ is an increasing sequence of position of real numbers and so tends to limit (say $l \geq 0$ ). If $l>0$, then we have

$$
d\left(f\left(x_{n+1}\right), f\left(x_{n+2}\right)\right) \leq d\left(\left(f\left(x_{n}\right), f\left(x_{n+1}\right)\right)-\psi(l)\right.
$$

Thus;

$$
d\left(f\left(x_{n+N}\right), f\left(x_{n+N+1}\right)\right) \leq d\left(\left(f\left(x_{n}\right), f\left(x_{n+1}\right)\right)-N \cdot \psi(l)\right.
$$

which is a contradiction for $\mathrm{N}$ is large enough. And so therefore $\lim _{n \rightarrow \infty} d\left(f\left(x_{n}\right), f\left(x_{n+1}\right)\right)=0$. Further more for $\mathrm{m}>\mathrm{n}$, $\left.f\left(x_{n+1}\right)\right) \leq d\left(\left(f\left(x_{n}\right), f\left(x_{n+1}\right)\right)+d\left(\left(f\left(x_{n+1}\right), f\left(x_{n+2}\right)\right)+\right.\right.$

$$
\ldots \ldots+d\left(\left(f\left(x_{m-1}\right), f\left(x_{m}\right)\right)\right.
$$


Using [2.4] and $\lim _{n \rightarrow \infty} d\left(f\left(x_{n}\right), f\left(x_{n+1}\right)\right)=0$, along with weakly contractivity of $\mathrm{T}$, with respect to $\mathrm{f}$, we obtain $\left\{d\left(f\left(x_{n}\right), f\left(x_{m}\right)\right)\right\} \rightarrow 0$, as $m, n \rightarrow \infty$.

View of (i), there is existence of sequence $\left\{x_{n}\right\}$ in $X$, such that $\operatorname{Lim}_{n \rightarrow \infty} f x_{n}=\operatorname{Lim}_{n \rightarrow \infty} T x_{n}=t \in X$.

As, $f(X)$ is a complete subspace of $X$, every sequence of $f(X)$,has a limit in $f(X)$. Therefore,

$\operatorname{Lim}_{n \rightarrow \infty} f x_{n}=t=f a=\operatorname{Lim}_{n \rightarrow \infty} T x_{n} ; a \in X$, which in turn yields that $t=f a \in f(X)$. Now, assert that $f a=T a$.

If not, then $d(f a, T a)>0$. Now solving;

$$
\begin{aligned}
& d\left(f\left(x_{n+1}\right), T(a)\right)=d\left(T\left(x_{n}\right), T(a)\right) \\
& \quad \leq d\left(f\left(x_{n}\right), f(a)\right)-\psi\left(d\left(f\left(x_{n}\right), f(a)\right)\right)
\end{aligned}
$$

Taking $\underset{n \rightarrow \infty}{\operatorname{Lim}}$, we get;

$$
d(t, T(a)) \leq d(t, f(a))-\psi(d(t, f(a)))
$$

Thence, $a$ is the solution of the functional equation $f(x)=T(x)$. Thus, the pair (f, T) has a common fixed point of coincidence.

Part II: We have obtained a point $a$ in $\mathrm{X}$, such that $T(a)=f(a)=t$, which satisfies occasionally weakly compatible map condition. So $f T(a)=T f(a)$ and as such $T t=f a$. To show that $f(t)=t$. If, we consider that it is not so, then we have $d(f(t), t)=d(T(a), T(t))$

$\leq d(f(a), f(t))-\psi(d(t, f(t)))$

$<d(t, f(t))$, which is a contradiction.

Hence the pair $(\mathrm{f}, \mathrm{T})$ has a common point of coincidence.

Remark 2.1: If $\mathrm{f}(\mathrm{X})=\mathrm{X}$ and $\mathrm{f}=i \mathrm{~d}_{\mathrm{x}}$ (identity map of $\mathrm{X}$ ), then we conclude from [2.1], that the sequence $\left\{x_{n}\right\}$ converges to affixed point of $\mathrm{T}$. Thus our Theorem 2.1 is a generalization theorem of Rhoades [14, Theorem 1].

Remark 2.2: If we define $\psi:[0, \infty) \rightarrow[0, \infty)$ by $\psi(t)=t-r(t)$ where $r:[0, \infty) \rightarrow[0, \infty)$ is a continuous function such that $r(t)<t$ for each $t>0$, we obtain the similar contractive condition as given by Pant[13, Theorem 1].

Example 2.1: Let $X=R$ with usual symmetric metric and let $T$ and $\mathrm{f}$ be given by

$$
\begin{aligned}
& T(x)=p x \quad ; p \neq 0 \\
& f(x)=q-r x ; r>0, q \neq 0,1,(r-1) \geq p
\end{aligned}
$$

Define $\psi:[0, \infty) \rightarrow[0, \infty)$ as $\psi(x)=x / r$

$$
\text { As } \begin{aligned}
d(f x, f y)-\psi(d(f x, f y))) & =(r-1)|x-y| \\
& \geq p|x-y| \\
& =d(T x, T y)
\end{aligned}
$$

Therefore, $\mathrm{T}$ is weakly contractive mapping with respect to f. For $\mathrm{p}>\mathrm{r}$, $\mathrm{T}$ is not f-nonexpansive map. Moreover, $\mathrm{T}$ and $\mathrm{f}$ have a common fixed point.

Theorem 2.2: Let $X$ be a normed space and $T$ be a weakly contractive mapping with respect to f, satisfying (E.A.) property. If $\mathrm{T}$ and $\mathrm{f}$ are occasionally weakly compatible and $\mathrm{f}(\mathrm{X})$ as a complete subspace of $\mathrm{X}$, then modified Mann iteration $\sum \alpha_{n}=\infty$ converges to a common fixed point of $\mathrm{f}$ and $\mathrm{T}$.

Proof: From Theorem 2.1, we obtain common fixed point $t$ of T and $\mathrm{f}$.

Consider

$$
\begin{aligned}
& \left\|y_{n}-t\right\|=\left\|\left(1-\alpha_{n}\right) f\left(x_{n}\right)+\alpha_{n} T\left(x_{n}\right)-f(a)\right\| \\
& =\left\|\left(1-\alpha_{n}\right) f\left(x_{n}\right)-f(a)+\alpha_{n} T\left(x_{n}\right)-T(a)\right\| \\
& \leq\left(1-\alpha_{n}\right)\left\|f\left(x_{n}\right)-f(a)\right\|+\alpha_{n}\left\|T\left(x_{n}\right)-T(a)\right\| \\
& \leq\left\|f\left(x_{n}\right)-f(a)\right\|-\alpha_{n} \psi\left(\left\|f\left(x_{n}\right)-f(a)\right\|\right) \\
& \leq\left\|y_{n-1}-t\right\|
\end{aligned}
$$

which gives $\operatorname{Lim}_{n \rightarrow \infty}\left\|y_{n}-t\right\|=r \geq 0$. Now if $\mathrm{r}>0$, then any fixed positive integer $\mathrm{N}$, we have

$$
\begin{aligned}
\sum_{n=N}^{\infty} \alpha_{n} \psi(r) & \leq \sum_{n=N}^{\infty} \alpha_{n} \psi\left(\left\|y_{n}-t\right\|\right) \\
& \leq \sum_{n=N}^{\infty}\left(\left\|y_{n-1}-t\right\|-\left\|y_{n}-t\right\|\right) \\
& <\left\|y_{N}-t\right\|
\end{aligned}
$$

which contradicts $\alpha_{n}$. Therefore the Mann iteration sequence converges to a common fixed point of $\mathrm{T}$ and $\mathrm{f}$.

Theorem 2.3: Let $X$ be a normed space and $T$ be a weakly contractive mapping with respect to $f$, satisfying (E.A.) property. If $\mathrm{T}$ and $\mathrm{f}$ are occasionally weakly compatible and $\mathrm{f}(\mathrm{X})$ is a complete subspace of $\mathrm{X}$. Suppose that two sequences $\left\{y_{n}\right\}$ and $\left\{z_{n}\right\}$ are defined as

$z_{n}=f\left(x_{n+1}\right)=\left(1-\alpha_{n}\right) f\left(x_{n}\right)+\alpha_{n} T\left(w_{n}\right)$ 
$y_{n}=f\left(w_{n}\right)=\left(1-\beta_{n}\right) f\left(x_{n}\right)+\beta_{n} T\left(x_{n}\right) ; n \geq 0 \quad$ where

$0 \leq \alpha_{n}<1,0<\beta_{n} \leq 1, \sum \alpha_{n} \beta_{n}=\infty$ and $x_{0} \in 0$, then the

iterative sequence converges $\left\{z_{n}\right\}$ to a common fixed point of $\mathrm{f}$ and $\mathrm{T}$.

Proof: Let $t$ be a common fixed point of $\mathrm{T}$ and $\mathrm{f}$, the existence of this fixed point of $\mathrm{T}$ and $\mathrm{f}$, follows from Theorem 2.1, So,

$$
\begin{aligned}
&\left\|z_{n}-t\right\|=\left\|\left(1-\alpha_{n}\right) f\left(x_{n}\right)+\alpha_{n} T\left(w_{n}\right)-t\right\| \\
& \leq\left(1-\alpha_{n}\right)\left\|f\left(x_{n}\right)-t\right\|+\alpha_{n}\left\|T\left(w_{n}\right)-T(a)\right\| \\
& \leq\left(1-\alpha_{n}\right)\left\|f\left(x_{n}\right)-t\right\|+\alpha_{n} \|\left(f\left(w_{n}\right)-t \|-\psi\left(\left\|f\left(w_{n}\right)-t\right\|\right)\right) \\
& \leq\left(1-\alpha_{n}\right)\left\|f\left(x_{n}\right)-t\right\|+\alpha_{n}\left(\|\left(1-\beta_{n}\right) f\left(x_{n}\right)+\right. \\
& \quad \beta_{n} T\left(x_{n}\right)-t \|-\psi\left(\left\|f\left(w_{n}\right)-t\right\|\right) \\
& \leq\left(1-\alpha_{n}\right)\left\|f\left(x_{n}\right)-t\right\|+\alpha_{n}\left(\left(1-\beta_{n}\right) \| f\left(x_{n}\right)-\right. \\
&\left.t\left\|+\beta_{n}\right\| T\left(x_{n}\right)-T(a) \|-\alpha_{n} \psi\left(\left\|f\left(w_{n}\right)-t\right\|\right)\right) \\
& \leq\left(1-\alpha_{n}\right)\left\|f\left(x_{n}\right)-t\right\|+\alpha_{n}\left(\left(1-\beta_{n}\right)\left\|f\left(x_{n}\right)-t\right\|+\right. \\
&\left.\beta_{n} \alpha_{n}\left[\left\|f\left(x_{n}\right)-t\right\|-\psi\left(\left\|f\left(x_{n}\right)-t\right\|\right)\right]-\alpha_{n} \psi\left(\left\|f\left(w_{n}\right)-t\right\|\right)\right) \\
& \leq\left\|f\left(x_{n}\right)-t\right\|-\beta_{n} \alpha_{n} \psi\left(\left\|f\left(x_{n}\right)-t\right\|\right)- \\
& \quad \alpha_{n} \psi\left(\left\|f\left(w_{n}\right)-t\right\|\right) \\
& \leq \quad \operatorname{gives} \quad \operatorname{Lim}_{n \rightarrow \infty}\left\|z_{n}-t\right\|=r \geq 0 .
\end{aligned}
$$

Suppose that $\mathrm{r}>0$, then for any fixed integer $\mathrm{N}$, we have

$$
\begin{aligned}
\sum_{n=N}^{\infty} \alpha_{n} \beta_{n} \psi(r) & \leq \sum_{n=N}^{\infty} \alpha_{n} \beta_{n} \psi\left(\left\|z_{n}-t\right\|\right) \\
& \leq \sum_{n=N}^{\infty}\left(\left\|z_{n}-t\right\|-\left\|z_{n+1}-t\right\|\right) \\
& \leq\left\|z_{N}-t\right\|
\end{aligned}
$$

which contradicts $\sum \alpha_{n} \beta_{n}=\infty$. Thereby the result follows.

\section{INVARIANT APPROXIMATIONS}

As an application of Theorem 2.1,we have the following results, involving the Invariant Approximations.

Theorem 3.1: Let $(X, d)$ be a symmetric space and let $\mathrm{T}$ be a weakly contractive mapping with respect to $f$, satisfying (E,A.) property. Assume that $\mathrm{T}$ leaves f-invariant compact subset $\mathrm{S}$ of closed subspace $\mathrm{f}(\mathrm{X})$ as invariant. If $\mathrm{f}$ and $\mathrm{T}$ are occasionally weakly compatible maps and $x_{0} \in F(T) \cap F(f)$ then, $P_{S}\left(x_{0}\right) \cap F(T) \cap F(f) \neq \phi$.
Proof: Since $S$ is a compact subset of $f(X)$, therefore $P_{S}\left(x_{0}\right) \neq \phi$. To show that $T\left(P_{S}\left(x_{0}\right)\right) \subseteq f\left(P_{S}\left(x_{0}\right)\right)$.

Assume on contrary that there exists $\gamma \in P_{S}\left(x_{0}\right)$ with $T(\gamma) \notin f\left(P_{S}\left(x_{0}\right)\right)$. Consider the function

$$
\begin{aligned}
& d\left(f(\gamma), x_{0}\right)=d\left(x_{0}, S\right) \leq d\left(x_{0}, T(\gamma)\right)=d\left(T\left(x_{0}\right), T(\gamma)\right) \\
& \left.\leq d\left(f\left(x_{0}\right), f(\gamma)\right)-\psi d\left(f\left(x_{0}\right), f(\gamma)\right)\right)<d\left(f(\gamma), x_{0}\right)
\end{aligned}
$$

, which is a contradiction. Hence this shows that $\gamma$ is a fixed point of convergence in $P_{S}\left(x_{0}\right)$. Now, since $f\left(P_{S}\left(x_{0}\right)\right)$ being, closed subset of complete symmetric space is complete, therefore $\mathrm{T}$ and $\mathrm{f}$ have a common fixed point in $P_{S}\left(x_{0}\right)$. Hence the result follows.

Theorem 3.2: Let $(X, d)$ be a symmetric space and let $\mathrm{T}$ be a weakly contractive mapping with respect to $f$, satisfying (E,A.) property. Assume that $\mathrm{T}$ leaves f-invariant compact subset $\mathrm{S}$ of closed subspace $\mathrm{f}(\mathrm{X})$ as invariant. Let $v \in X$ and for each $\gamma \in P_{S}(v), d(x, T(\gamma))<d(x, f(\gamma))$ and $f(\gamma) \in P_{S}(v)$. If $\mathrm{f}$ and $\mathrm{T}$ are occasionally weakly compatible maps, then $v$ is the best approximation in $\mathrm{S}$, which is also the common fixed point of f and T.

Proof: Since $S$ is a compact subset of $f(X)$, therefore $P_{S}\left(x_{0}\right) \neq \phi$. Since $\mathrm{f}$ and $\mathrm{T}$ are occasionally weakly compatible maps, so for $T x \in f x$, there exists $f T x \subseteq T f x$ and hence $T\left(P_{S}\left(x_{0}\right)\right) \subseteq f\left(P_{S}\left(x_{0}\right)\right)$. On contrary, assume that there exists $\gamma$ in $P_{S}\left(x_{0}\right)$ with $T(\gamma) \notin f\left(P_{S}\left(x_{0}\right)\right)$.

So, $\quad d(f(\gamma), v)=f(v, S)$

$\leq d(v, T(\gamma))<d(v, f(\gamma))<d(v, S)$.

This contradiction leads to $T\left(P_{S}\left(x_{0}\right)\right) \subseteq f\left(P_{S}\left(x_{0}\right)\right)$. Now as $f\left(P_{S}\left(x_{0}\right)\right)$ being closed subset of complete symmetric space is complete. So, $v$ has a best approximation in $\mathrm{S}$, which is also common fixed point of $f$ and $T$. 


\section{REFERENCES}

[1] M.Aamri and D.El. Moutawki, Some new common fixed point theorems under strict contractive conditions, J. Math. Anal. Appl. 270(2002), 181-188.

[2] M.A.Al.Thagafi, Common fixed points and best approximations, J.Approx.Theory 85(1996), 318-323.

[3] Ya.I.Alber and S.Guerre Delabriere, Principle of weakly contractive mappings in Hilbert spaces, New results in Operator Theory and its Applications, Oper.Theory Adv.Appl.Vol.98, Birkhauser, Basel, (1997), 7-22.

[4] I.Beg abd M.Abbhas, Fixed points and best approximations in Menger convex metric spaces, Arch. Mathematicum, 41 (2005), 389-397.

[5] B.Browski, Fix pointsin best approximations theory, Mathematica-Reven d'Analyse Numerique et de Theorie de l'Approx. 11(34), (1969), 195-220.

[6] T.L.Hicks, Fixed point theory in symmetric spaces with application to probabilistic spaces, Non linear analysis, 36(1999), 331-344.

[7] G.Jugck, Common fixed points for commuting and compatible mappings on compacta, Proceedings of Ametrican Mathematical Society 103(1998),no.3, 977-983.

[8] G.Jugck, Compatible mappings and common fixed points, Int.J.Math.Math.Sci.,9(1986), 771-779.

[9] G.Jugck and B.E.Rhoades, Fixed points for occasionally weakly compatible mappings, Fixed point Theory, vol.7, no.2, (2006), 287-296.
[10] G.Jugck and B.E.Rhoades, Fixed points for set valued functions without continuity, Indian J. Pure and Appl. Math.29(1998), no.3, 227-238.

[11] T.Kamran, Coincidence and fixed points for Hybrid strict contractions, Journal of Mathematical Analysis andApplications, 299(2004), no.1, 235-241.

[12] G,Meinardus, Invariant bei linearen Appprox., Archive for Rational Mechanics and Analysis, 14(1963), 301-303.

[13] R.P.Pant, Common fixed points of Non commuting mappings, J.Math.Anal.\&Appl., 188(1994),no.2, 436-440.

[14] B.E.Rhoades, Some theorems on weakly contractive maps, Non linear Anal. 47(2001), no.4, 2683-2693.

[15] B.E.Rhoades, Comments on two fixed point Iteration methods, J. Math. Anal. Appl. 56(1976), no. 3, 741- 750.

[16] S.Sessa, On weak commutativity condition of mapping in fixed point consideration, Publ. Inst. Math.(Beograd)N,S.,32(46), (1982), 149-153.

[17] N,Shahzad, Invariant Appriximations, Generalized Icontractions and R-Sub weakly commuting maps, Fixed Point Theory and Appl. ,1(2005), 79-86.

[18] W.A.Wilson, On Semi Metric spaces, Amer. J. Math, 53,(1931), 361-373.

[19] Al-Thagafi, M. A.; Shahzad, Naseer. Generalized \$ISnonexpansive selfmaps and invariant approximations. Acta Math. Sin. (Engl. Ser.) 24 (2008), no. 5, 867--876 